\title{
Self-rated oral health status and social and health determinants among community dwelling adults in Kenya
}

\author{
Supa Pengpid ${ }^{1,2}$, Karl Peltzer ${ }^{3,4}$
}

1. Asean Institute for Health Development, Mahidol University, Salaya, Phutthamonthon, Nakhonpathom, Thailand.

2. Department of Research and Innovation, University of Limpopo, Turfloop, South Africa.

3. Department for Management of Science and Technology Development, Ton Duc Thang University, Ho Chi Minh City, Vietnam.

4. Faculty of Pharmacy, Ton Duc Thang University, Ho Chi Minh City, Vietnam.

\begin{abstract}
Background: The aims of this study were to estimate the self-rated oral health status and its associated factors in a national community dwelling population in Kenya.

Methods: A cross-sectional study based on a stratified cluster random sampling was conducted in 2015. The total sample included 4,459 individuals 18-69 years $(M=40.4$ years, $S D=13.9)$. Questionnaire interview, blood pressure and anthropometric measurements, and biochemistry tests were conducted, including questions on the oral health status, general health status, oral health behaviour and socio-demographic information.

Results: Overall, $13.7 \%$ of participants reported poor self-rated oral health. In adjusted logistic regression analysis, older age (Odds Ratio-OR: 1.70, Confidence Interval-CI: 1.07, 2.69), having a lower number lover number of teeth (OR: 0.19, CI: 0.06, 0.62), having dentures (OR: 1.92, CI: 1.22, 3.03), having pain in the mouth or teeth (OR: 5.62, CI: 3.58, 8.90), impaired Oral Health Related Quality of Life (OR: 3.01, CI: 2.03, 4.47) and frequent soft drink consumption (OR: 3.62, CI: 1.89, 6.97) were associated with poor self-rated oral health.

Conclusion: High unsatisfied self-rated oral health status was found and several risk factors for poor self-rated oral health were identified that can help in guiding oral health care programming in Kenya.

Keywords: Self-rated oral health status, oral conditions, oral health behaviour, general health status, general health behaviour, adults, Kenya.
\end{abstract}

DOI: https://dx.doi.org/10.4314/ahs.v19i4.37

Cite as: Pengpid S, Peltzer K. Self-rated oral health status and social and health determinants among community dwelling adults in Kenya. Afri Health Sci.2019;19(4):3146-3153. https:// dx.doi.org/10.4314/abs.v19i4.37

\section{Introduction}

"Oral diseases are major public health problems worldwide and poor oral health has a profound effect on general health and quality of life."1 With patient-centred health care, the assessment of the biopsychosocial dimension of oral health, such as self-rated oral health status, has become increasingly important, taking both physical and psychosocial dimension of health into account. ${ }^{1}$ The perception of one's oral health status is relevant, since it is related to the utilization of dental services and the under-

\section{Corresponding author: \\ Karl Peltzer, Ton Duc Thang University, \\ Ho Chi Minh City, Vietnam \\ Email: karl.peltzer@tdt.edu.vn}

standing of its determinants can help in improving dental health care. ${ }^{2}$ Self-perceived oral health has been found to be significantly associated with clinical oral health status. ${ }^{3}$ There is scarce information on self-rated oral health and its determinants among community dwelling adults in Africa countries, including Kenya.4-6 Perceptions of oral health status and its determinants such as oral health behaviours depend on their sociocultural context, which may differ in Kenya compared to high-income countries in other world regions. ${ }^{1,2}$

In a national survey among adults in Kenya (35-44 years and 65 years of more), $17.0 \%$ rated their gums as poor and $18.5 \%$ rated their teeth as poor, 6 in a general adult population in South Africa, 23.7\% rated their oral health as neither good nor bad, poor or very poor, ${ }^{4}$ in Nigeria $9 \%$ as poor or very poor, ${ }^{5}$ in Australia $17.0 \%$ as fair or

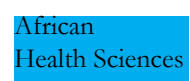

(C) 2019 Pengpid et al. Licensee African Health Sciences. This is an Open Access article distributed under the terms of the Creative commons Attribution License (https://creativecommons.org/licenses/BY/4.0), which permits unrestricted use, distribution, and reproduction in any medium, provided the original work is properly cited. 
poor, ${ }^{7}$ in USA $34.4 \%$ as "fair" or "poor." ${ }^{8}$ Among adults (35-44 years) in North-Eastern Brazil, 63\% reported a negative self-perception of oral health, ${ }^{9}$ in Istanbul, Turkey, $65 \%$ poor oral health status, ${ }^{10}$ and among adults in Qatar 5.9\% and 4.6\% rated their teeth and gums, respectively, as poor. ${ }^{11}$

Factors associated with self-rated oral health include sociodemographic factors, oral conditions, general health status variables, oral health behaviour, and general health behaviour.

Sociodemographic risk factors for poor self-rated oral health include, deceasing age, 10 older age, ${ }^{7,12}$ being female or male , $7,11-13$ and low socioeconomic status., ${ }^{4,7,9,11,13,14}$ Oral conditions increasing the risk for poor self-rated oral health include lesser number of teeth, ${ }^{15}$ recent bleeding gum, tooth sensitivity, and recent bad breath, ${ }^{4}$ dental caries, ${ }^{16}$ toothache, ${ }^{17}$ and dental pain. ${ }^{18}$ General health status risk factors for poor self-rated oral health include comorbidity, chronic conditions, ${ }^{14}$ overweight and obesity, ${ }^{19,20}$ and diabetes. ${ }^{11}$

Oral health risk behaviour factors for poor self-rated oral health include inadequate tooth brushing, ${ }^{4}$ low oral hygiene behaviours, ${ }^{12}$ irregular dental attendance, ${ }^{10}$ dentist visits $>3$ years ago, ${ }^{9}$ no past use of dental services, ${ }^{4}$ no routine dental check, ${ }^{21}$ dental attendance, ${ }^{14}$ dental treatment, dental check-ups, ${ }^{22}$ and frequent dental visiting. ${ }^{23}$ General health risk behaviour factors for poor self-rated oral health include substance use such as current smoking, ${ }^{4,714,24}$ smokeless tobacco use, ${ }^{11}$ problem drinking ${ }^{7,4}$ Khat use, ${ }^{25}$ poor diets, ${ }^{24}$ food avoidance (in particular, whole fruits and raw vegetables), ${ }^{26}$ and physical inactivity. $^{27}$

The aims of this study were to estimate the self-rated oral health status and its associated factors in a national adult community dwelling population in Kenya.

\section{Methods}

\section{Study design and participants}

A multi-stage cluster sampling method (200, 100 urban and 100 rural clusters, 30 households and one adult per household) was used to select adults aged 18 to 69 years for the Kenya STEPS Survey in 2015, more details of sample design. ${ }^{28}$ A total of 4,459 individuals had complete oral health measurements. The response rate for STEP 1 was 95\%, STEP 2 and 3 was 93\%.

The protocol of the STEPS survey was reviewed and approved by the Kenya Ministry of Health Ethics Com- mittee. Prior to study participation, respondents had to provide informed consent.

\section{Measures}

Following WHO STEPS methodology,28 two steps were taken: "step 1, questionnaire interview, and step 2, anthropometric measurements. For step 1, handheld devices loaded with eSTEPS software and WHO STEPS questionnaire were used by trained data collectors at respondents' residences. Questions included tobacco use, Khat use (chewing), alcohol consumption, dietary habits, and the amount of physical activity (PA), raised total cholesterol (TC), cardiovascular diseases, and sociodemographic profiles. Show cards on different types of tobacco products, alcohol, physical activities, and servings of fruits and vegetables were used to facilitate understanding of the questions by the respondents." 28

Self-rated oral health status was assessed with two questions, 1) "How would you describe the state of your teeth, and 2) gums?" Response options ranged from $1=$ excellent to $6=$ very poor. ${ }^{28}$ (Cronbach alpha 0.70 ). Poor self-rated oral health status was classified as having poor or very poor status of teeth and/or gums, and good oral health as having average to excellent status of teeth and/or gums.

\section{Oral conditions}

Tooth loss was assessed with the question, "How many natural teeth do you have?" (Response options: 1=no natural teeth, 2=1-9 teeth, 10-19 teeth, and 20 teeth or more) ${ }^{28}$ Responses were classified into having 0-19 teeth and 20 or more teeth.

Dentures. "Do you have any removable dentures?" (Yes, $\mathrm{No}){ }^{28}$

Oral health related quality of life was assessed with 10 items, e.g., "Difficulty in chewing foods?"(Yes, No) (Cronbach alpha 0.89).

Physical symptoms were asked with the question, "During the past 12 months, did your teeth or mouth cause any pain or discomfort?" (Yes, No $)^{28}$

Oral health behaviours were assessed with seven questions: ${ }^{28}$

1) "What is the main source of your home drinking water?” (Responses were grouped into 1=piped supply and $0=$ well or underground water, rain water, spring water, surface water);

2) "How often do you clean your teeth?" (Response options: $1=$ never to 7 twice or more a day); 3 ) "Do you use 
toothpaste containing fluoride?"(Yes or No); 3) "How long has it been since you last saw a dentist?" (Response options: $1=$ less than 6 months to $6=$ never received dental care); 4) "How long has it been since you last saw a dentist?" (Responses ranged from $1=$ less than 6 month ago to $6=$ never); 5) "Consumption of soft drinks (like Fanta, coca cola, 7-up, Aya, Softa, Vimto or other sugary drinks?"(Responses: Number of days in a week and number of servings in one day); 6) "Consumption of processed food high in sugar (biscuits, wafers, cakes, candy, sweets and chocolate?" Responses ranged from $1=$ always (every meal) to $5=$ never; and 7) "Adding sugar to your beverages?" (Responses ranged from 1=always (every drink) to $5=$ never).

Daily fruit and vegetable consumption were calculated from the number of servings consumed per day in a typical week (Cronbach's alpha 0.76).28 Physical activity level was measured based on the duration of moderate and vigorous physical activities (at work, transport and recreation) in a typical day and week. Physical activity levels were calculated into low, moderate or high, as per WHO Global Physical Activity Questionnaire (GPAQ). ${ }^{29}$ Past month binge drinking was assessed by asking participants how many times they had "six or more standard alcoholic drinks in a single drinking occasion during the past 30 days."28

Steps 2 and 3 were conducted at the village; the field survey team coordinated with the village authority for selecting the appropriate place for steps 2 and 3. It involved "taking anthropometric measurements, fasting blood samples, by trained health staff and research assistants using WHO STEPS standard methodology. ${ }^{30}$ Participants' heights and weights were assessed with standard measures. Body mass index (BMI) was calculated according to World Health Organization31 criteria: underweight $<1850$ (BMI kg/m²), normal weight (18.50 to $24.99 \mathrm{~kg} /$ $\mathrm{m} 2)$, overweight and obese $\left(\geq 25.00 \mathrm{~kg} / \mathrm{m}^{2}\right)$.

\section{Data analysis}

Post stratification adjustments were done to align with the population projections according to age-sex categories. Descriptive statistics on frequency, weighted prevalence and $95 \%$ confidence intervals (CI) was performed for sociodemographic, behavioural, health and oral health variables. Multivariable logistic regression was conducted to assess associations between sociodemographic factors, oral and general health variables and poor oral health status. Variables from bivariate analysis with a significant level of $\mathrm{p}<0.05$ were included in the multivariable logistic model. Multi-collinearity was checked with variance inflation factor; none exceeded a value of 2.3. $\mathrm{P}<0.05$ was considered significant. Missing values $(<5 \%)$ were excluded from the analysis. All analyses were adjusted for the multi-stage sample design and conducted with STATA software version 13.0 (Stata Corporation, College Station, TX, USA).

\section{Results \\ Sample characteristics}

The sample included 4.459 adults (40\% males and 60\% females) aged 18 to 69 years, mean age 40.4 years $(S D=13.9)$. More than half of the participants $(58.8 \%)$ had completed primary or more education, and $51.2 \%$ were residing in rural areas. Regarding oral conditions, $2.2 \%$ reported to have $0-19$ natural teeth, $4.6 \%$ removable dentures, $31.6 \%$ experienced pain in the teeth of mouth in the past 12 months, and 35.5\% had impaired Oral Health Related Quality of Life (yes, on any of the 10 items). In terms of general health status, $5.6 \%$ of the participants reported to have been diagnosed with stroke, angina or heart attack, $27.8 \%$ were overweight or had obesity, and 2.6\% were measured to have diabetes. In relation to oral health behaviour, $38.1 \%$ used piped water as a source of home drinking water, $35.8 \%$ cleaned their teeth twice or more times a day, $72.0 \%$ used a toothpaste with fluoride, $10.5 \%$ had seen a dentist in the past year, $4.1 \%$ consumed soft drinks 6-7 days a week, 6.1\% ate processed food high in sugar daily, and $35.7 \%$ added sugar to beverages daily. Regarding general health behaviour, $8 \%$ of particiants were current Khat users, $8.3 \%$ current smokers, 3.6\% current smokeless tobacco users, $13.5 \%$ were past month binge drinkers, $10.9 \%$ were physically inactive, and $80.1 \%$ ate insufficient fruit and vegetables and. Overall, 13.7\% of participants reported poor self-rated oral health.

In bivariate analysis, having oral conditions (tooth loss, dentures, pain in teeth or mouth, and impaired Oral Health Related Quality of Life), poorer general health status (having stroke, angina or heart attack), lack of fluoride toothpaste use, dental care attendance, and soft drink consumption were associated with poor self-rated oral health. General health risk behaviours were not found significantly associated with poor self-rated oral health (see Table 1). 
Table 1: Sample characteristics

\begin{tabular}{|c|c|c|c|c|}
\hline Variable & & $\begin{array}{l}\text { Sample } \\
\text { N (\%) }\end{array}$ & $\begin{array}{l}\text { Self-rated poor oral } \\
\text { health } \\
\mathrm{n}(\%)\end{array}$ & $\begin{array}{l}\text { Chi- } \\
\text { square } \\
\text { P-value } \\
\end{array}$ \\
\hline \multicolumn{5}{|l|}{ Sociodemographic variables } \\
\hline All & & 4459 & 13.7 & \\
\hline \multirow[t]{4}{*}{ Age in years } & $18-29$ years & $1486(33.3)$ & 11.2 & $<0.001$ \\
\hline & $30-44$ & $1705(38.2)$ & 15.0 & \\
\hline & $45-59$ & $871(19.5)$ & 14.9 & \\
\hline & $60-69$ & $397(8.9)$ & 24.3 & \\
\hline \multirow[t]{2}{*}{ Sex } & Female & $2675(60.0)$ & 16.7 & $<0.001$ \\
\hline & Male & $1784(40.0)$ & 10.5 & \\
\hline \multirow[t]{4}{*}{ Education } & No formal schooling & $746(16.7)$ & 16.5 & 0.311 \\
\hline & Primary school incomplete & $1090(24.4)$ & 15.7 & \\
\hline & Primary school complete & $1415(31.7)$ & 13.6 & \\
\hline & Secondary school and above & $1208(27.1)$ & 11.1 & \\
\hline \multirow[t]{5}{*}{ Wealth quintle } & Poorest & $894(19.0)$ & 15.1 & 0.162 \\
\hline & Second & $891(20.8)$ & 17.1 & \\
\hline & Middle & $892(18.2)$ & 14.3 & \\
\hline & Fourth & $892(18.7)$ & 10.5 & \\
\hline & Richest & $890(23.3)$ & 11.7 & \\
\hline \multirow[t]{2}{*}{ Geolocality } & Rural & 2289 & 14.1 & 0.633 \\
\hline & Urban & 2174 & 13.1 & \\
\hline \multicolumn{5}{|l|}{ Oral conditions } \\
\hline \multirow[t]{2}{*}{ Number of teeth } & $\geq 20$ & $4342(97.8)$ & 12.7 & $<0.001$ \\
\hline & $0-19$ & $110(2.2)$ & 62.7 & \\
\hline \multirow[t]{2}{*}{ Dentures (removable) } & No & $4140(95.4)$ & 13.1 & $<0.001$ \\
\hline & Yes & $316(4.6)$ & 24.8 & \\
\hline \multirow[t]{2}{*}{ Pain in teeth or mouth in the past 12 months } & No & $2952(68.4)$ & 4.2 & $<0.001$ \\
\hline & Yes & $1504(31.6)$ & 34.2 & \\
\hline \multirow[t]{2}{*}{ Impaired Oral Health Related Quality of Life } & No & $3060(71.8)$ & 5.1 & $<0.001$ \\
\hline & Yes & $1395(28.2)$ & 35.5 & \\
\hline \multicolumn{5}{|l|}{ General health status } \\
\hline Overweight or obesity & No & $2932(72.2)$ & 13.1 & 0.093 \\
\hline & Yes & $1324(27.8)$ & 15.9 & \\
\hline Diabetes & No & $4000(97.4)$ & 13.6 & 0.140 \\
\hline & Yes & $148(2.6)$ & 19.2 & \\
\hline Stroke, angina or heart attack & No & $4163(94.4)$ & 12.9 & 0.002 \\
\hline & Yes & $293(5.6)$ & 26.3 & \\
\hline Oral health behaviour & & & & \\
\hline Home drinking water source & Other sources (spring, well) & $2705(61.9)$ & 12.2 & 0.943 \\
\hline & Piped water & $1502(38.1)$ & 13.3 & \\
\hline Tooth cleaning & $<$ twice a day & $2771(64.2)$ & 14.2 & 0.520 \\
\hline & twice or more/day & $1684(35.8)$ & 12.7 & \\
\hline Uses toothpaste & without fluoride & $1425(28.0)$ & 16.9 & 0.039 \\
\hline & with fluoride & $2905(72.0)$ & 12.2 & \\
\hline Saw dentist within the past 12 month & No & $3953(89.5)$ & 12.1 & $<0.001$ \\
\hline & Yes & $502(10.5)$ & 27.2 & \\
\hline Soft drinks & $<6-7$ days/week & $4275(95.9)$ & 13.0 & 0.003 \\
\hline & 6-7 days/week & $181(4.1)$ & 31.0 & \\
\hline Processed food high in sugar & Less than daily or never & $4192(93.9)$ & 13.6 & 0.634 \\
\hline & Daily, every meal & $261(6.1)$ & 15.3 & \\
\hline Add sugar to beverages & $<$ Every day/every drink & $2488(64.3)$ & 12.9 & 0.283 \\
\hline & Every day/every drink & $1666(35.7)$ & 15.0 & \\
\hline General health behaviour & & & & \\
\hline Current Khat user & No & $4173(93.1)$ & 13.7 & 0.796 \\
\hline & Yes & $286(6.9)$ & 12.9 & \\
\hline Current daily smoker & No & $4135(91.7)$ & 13.6 & 0.837 \\
\hline & Yes & $324(8.3)$ & 14.2 & \\
\hline Past daily smoker & No & $3882(95.0)$ & 13.6 & 0.427 \\
\hline & Yes & $195(5.0)$ & 16.0 & \\
\hline Current smokeless tobacco user & No & $4275(96.4)$ & 13.6 & 0.671 \\
\hline & Yes & $181(3.6)$ & 15.2 & \\
\hline Past daily smokeless tobacco user & No & $4225(99.0)$ & 15.4 & 0.138 \\
\hline & Yes & $49(1.0)$ & 23.4 & \\
\hline Binge drinking (past month) & No & $3979(86.5)$ & 14.0 & 0.291 \\
\hline & Yes & $480(13.5)$ & 11.5 & \\
\hline Physically inactive & No & $3834(10.9)$ & 13.6 & 0.456 \\
\hline & Yes & $527(89.1)$ & 11.6 & \\
\hline Inadequate fruit and vegetable consumption & No & $1031(19.9)$ & 13.5 & 0.890 \\
\hline & Yes & $3424(80.1)$ & 13.7 & \\
\hline
\end{tabular}

Oral health related quality of life and self-rated oral their oral health as poor reported impacts for all the ten health status

Significantly higher proportions of individuals who rated items than those who rated their oral health as average or good. All the differences were significant at $\mathrm{p}<0.001$ (see Table 2). 
Table 2: Oral health related quality of life by self-rated oral health status

\begin{tabular}{llll}
\hline $\begin{array}{l}\text { Oral Health Related Quality of } \\
\text { Life }\end{array}$ & Overall & $\begin{array}{l}\text { Poor } \\
\text { oral } \\
\text { health } \\
\%\end{array}$ & $\begin{array}{l}\text { Average or } \\
\text { good } \\
\text { oral gealth } \\
\%\end{array}$ \\
\hline Difficulty in chewing/biting & $1187(23.4)$ & 62.8 & 17.2 \\
Sleep often interrupted & $791(15.9)$ & 46.3 & 11.2 \\
Doing usual activities & $581(12.2)$ & 38.2 & 8.1 \\
Days taken off work & $518(10.8)$ & 32.7 & 7.4 \\
Feel tense & $449(9.2)$ & 31.1 & 5.8 \\
Reduced social activities & $337(7.2)$ & 24.2 & 4.6 \\
Difficulty with speech & $298(6.0)$ & 18.3 & 4.0 \\
Avoid smiling & $280(5.6)$ & 21.2 & 3.2 \\
Embarrassed about teeth & $221(4.9)$ & 19.1 & 2.7 \\
Less tolerant of spouse & $159(3.1)$ & 12.5 & 1.6 \\
someone close with & & & \\
\hline Overall impact & $1402(28.2)$ & 73.5 & 21.1 \\
\hline
\end{tabular}

\section{Associations with poor self-rated oral health}

In multivariable logistic regression analysis, older age (Odds Ratio=OR: 1.70, Confidence Interval=CI: 1.07, 2.69), having a lover number of teeth (OR: 0.19, CI: 0.06, 0.62), having dentures (OR: 1.92, CI: 1.22, 3.03), having pain in the mouth or teeth (OR: 5.62, CI: 3.58, 8.90), impaired Oral Health Related Quality of Life (OR: 3.01, CI: 2.03, 4.47) and frequent soft drink consumption (OR: 3.62, CI: 1.89, 6.97) were associated with poor self-rated oral health (see Table 3).

Table 3: Associations with poor self-rated oral health status

\begin{tabular}{|c|c|c|}
\hline Variables & $\mathrm{AOR}(95 \% \mathrm{CI})$ & P-value \\
\hline \multicolumn{3}{|l|}{ Age } \\
\hline $18-29$ years & 1 (Reference) & \\
\hline $30-44$ & $1.25(0.94,1.66)$ & 0.123 \\
\hline $45-59$ & $1.10(0.72,1.69)$ & 0.658 \\
\hline $60-69$ & $1.70(1.07,2.69)$ & 0.025 \\
\hline \multicolumn{3}{|l|}{ Sex } \\
\hline Female & 1 (Reference) & \\
\hline Male & $0.82(1.60,1.13)$ & 0.231 \\
\hline \multicolumn{3}{|c|}{ Stroke, angina or heart attack } \\
\hline No & 1 (Reference) & \\
\hline Yes & $1.70(0.99,2.92)$ & 0.054 \\
\hline \multicolumn{3}{|l|}{ Number of teeth } \\
\hline $0-19$ & 1 (Reference) & \\
\hline 20 or more & $0.19(0.06,0.62)$ & 0.006 \\
\hline \multicolumn{3}{|c|}{ Dentures (removable) } \\
\hline No & 1 (Reference) & \\
\hline Yes & $1.92(1.22,3.03)$ & 0.005 \\
\hline \multicolumn{3}{|c|}{ Pain in teeth or mouth in the past 12 months } \\
\hline No & 1 (Reference) & \\
\hline Yes & $5.62(3.58,8.90)$ & $<0.001$ \\
\hline \multicolumn{3}{|c|}{ Impaired Oral Health Related Quality of Life } \\
\hline No & 1 (Reference) & \\
\hline Yes & $3.01(2.03,4.47)$ & $<0.001$ \\
\hline \multicolumn{3}{|l|}{ Soft drinks } \\
\hline$<6-7$ days/week & 1 (Reference) & \\
\hline 6-7 days/week & $3.62(1.89,6.97)$ & $<0.001$ \\
\hline \multicolumn{3}{|l|}{ Uses toothpaste } \\
\hline without fluoride & 1 (Reference) & \\
\hline with fluoride & $0.76(0.56,1.05)$ & 0.097 \\
\hline \multicolumn{3}{|c|}{ Saw dentist within the past 12 month } \\
\hline No & 1 (Reference) & \\
\hline Yes & $0.77(0.55,1.07)$ & 0.124 \\
\hline
\end{tabular}




\section{Discussion}

This study assessed self-rated oral health and its correlates in a nationally representative adult community dwelling population in Kenya. High reports of poor (13.7\%) self-rated oral health were found in this study, which seem to be higher than in several previous surveys in different countries, ${ }^{4,5,7,8,11}$ and similar to a previous national survey among adults (35-44 years and 65 years of more) in Kenya.6 The high prevalence of self-rated poor oral health in this study may be an indication of a high burden of oral health problems and unmet treatment need in this population in Kenya. Responding to the question, what they did when they had any pain or discomfort with their teeth or mouth the last time, $27.9 \%$ said "nothing", $46.3 \%$ self-medication or pharmacy/dispensary, and only $20.8 \%$ consulted a public or private medical institution (analysis not shown).

In agreement with several previous studies, ${ }^{7,12}$ this study found that older age was associated with poorer self-rated oral health. Although in bivariate analysis the prevalence of poor self-rated oral health was higher in women than in men in this study, but this became non-significant in the multivariable model. Previous studies ${ }^{4,7,11-13}$ also found mixed results regarding gender differences in the prevalence of self-rated oral health. In contrast to previous studies, $4,7,9,11,13,14$ this study did not find an association between socioeconomic status risk factors and poor self-rated oral health.

Consistent with previous studies, ${ }^{15,17,18,32}$ this study found that having various oral conditions (tooth loss, dentures, pain in teeth or mouth and impaired Oral Health Related Quality of Life), increased the risk for poor self-rated oral health. In bivariate analysis, this study found an association between having chronic conditions (stroke, angina or heart attack) and poor self-rated oral health. Previous studies, 14 also found an association with chronic conditions and poor oral health status. In contrast to some previous studies, ${ }^{11,19,20}$ this study did not find an association between overweight and obesity, diabetes and self-rated oral health.

In bivariate analysis, lack of fluoride toothpaste use was associated with poor self-rated oral health, while no association was found between poor tooth cleaning practices and poor self-rated oral health. It is possible that because of the overall low prevalence of adequate tooth cleaning (38.1\%), no such differences were found in terms of oral health status. Inadequate tooth brushing and poor oral hygiene practices have been found associated with poor self-rated oral health in previous studies. ${ }^{4,12}$ Previous studies found mixed results in relation to low or high dental attendance and poor self-rated oral health status, ${ }^{4,9,10,14,21-23}$ while this study, in agreement with some studies, ${ }^{14,22,23}$ found a positive relationship between dental attendance and poor self-rated oral health status in bivariate but not multivariable analysis. Among our study participants who had consulted a dentist, the majority $(92.8 \%)$ consulted a dentist the last time because of pain or treatment and only $3.4 \%$ had gone for a preventative check-up (analysis not shown). This may explain as to why dental attendance was correlated with poor self-rated oral health status in bivariate analysis. Further, the frequent consumption of soft drinks was significantly associated with poor self-rated oral health in this study. Previous studies, ${ }^{33}$ have found an association between soft drink consumption and oral disease.

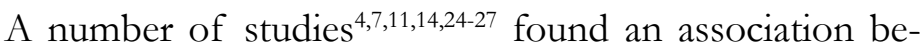
tween substance use, problem drinking, inadequate fruit and vegetable consumption, physical inactivity and poor self-rated oral health, while in this study did not find any such association. This finding seems to show a lack of clustering pattern of oral and general health-risk behaviours, except for high sugar intake in the form of soft drink consumption. ${ }^{34}$

\section{Study limitations}

The study design was cross-sectional; therefore, no causative conclusions can be drawn. All oral health assessment measures used in this study were by self-report, which may have biased responses. "Generally, patients are less likely to adequately assess their periodontal status and the presence of caries than they are to assess the number of their teeth, restorations, and the presence of fixed and removable prosthetics." ${ }^{\prime 35}$ In future studies oral examinations should be performed, in addition to self-reported oral health measures. Furthermore, the reference period for asking about pain or discomfort in teeth or mouth was 12 months, which may have caused a recall bias.

\section{Conclusion}

High unsatisfied self-rated oral health status was found and several risk factors (various oral conditions, and oral health risk behaviour) were identified that can help in guiding oral health care programming in Kenya.

\section{Competing interests}

The authors declare that they have no competing interest. 


\section{Acknowledgements}

We are grateful to the Kenya National Bureau of Statistics (KNBS) for making the STEPS survey Kenya 2015 available.

\section{References}

1. Petersen PE, Bourgeois D, Ogawa H, Estupinan-Day $\mathrm{S}$, Ndiaye $\mathrm{C}$. The global burden of oral diseases and risks to oral health. Bull World Health Organ 2005; 83(9): 661-9. 2. Perera I, Ekanayake L. Factors influencing perception of oral health among adolescents in Sri Lanka. Int Dent J 2008; 58: 349-355.

3. Blizniuk A, Ueno M, Zaitsu T, Kawaguchi Y. Association between self-reported and clinical oral health status in Belarusian adults. J Investig Clin Dent 2017;8(2). doi: 10.1111/jicd.12206.

4. Olutola BG, Ayo-Yusuf OA. Socio-environmental factors associated with self-rated oral health in South Africa: a multilevel effects model. Int J Environ Res Public Health 2012;9(10):3465-83. doi: 10.3390/ijerph9103465.

5. Olusile AO, Adeniyi AA, Orebanjo O. Self-rated oral health status, oral health service utilization, and oral hygiene practices among adult Nigerians. BMC Oral Health 2014;14: 140. doi: 10.1186/1472-6831-14-140.

6. Ministry of Health. Kenya National Oral Health Survey Report 2015. Available at https://profiles.uonbi. ac.ke/gathece/files/kenya_national_oral_health_survey_report_2015.pdf\&gt (accessed 17 August 2018).

7. Mejia G, Armfield JM, Jamieson LM. Self-rated oral health and oral health-related factors: the role of social inequality. Aust Dent J 2014;59:226-33. doi: 10.1111/ adj.12173.

8. Morin NM, Dye BA, Hooper TI. Influence of cigarette smoking on the overall perception of dental health among adults aged 20-79 years, United States, 1988-1994. Public Health Rep 2005;120(2):124-32.

9. Vale EB, Mendes Ada C, Moreira Rda S. Self-perceived oral health among adults in Northeastern Brazil. Rev Saude Publica 2013;47 Suppl 3:98-108.

10. Peker K. The Determinants of Self-Rated Oral Health in Istanbul Adults (pp. 171-188), Oral Health Care - Pediatric, Research, Epidemiology and Clinical Practices, Prof. Mandeep Virdi (Ed.), 2012. ISBN: 978-953-510133- 8, InTech, Available from: http:/ /www.intechopen. com/books/oral-health-care-pediatric-research-epidemiologyand-clinical-practices/the-determinants-of-selfrated-oral-health-in-istanbul-adults (accessed 3 August 2018).
11. Cheema S, Maisonneuve P, Al-Thani MH, et al. Oral health behavior and factors associated with poor oral status in Qatar: results from a national health survey. J Public Health Dent 2017;77(4):308-316. doi: 10.1111/jphd.12209. 12. Nico LS, Andrade SS, Malta DC, Pucca Júnior GA, Peres MA. Self-reported oral health in the Brazilian adult population: results of the 2013 National Health Survey. Cien Saude Colet 2016;21(2):389-98. doi: 10.1590/141381232015212.25942015.

13. Kwon M-H, Choi H-S. Association of Gender, Education, Income and Self- Perceived Oral Health Status among the Koreans; The 6th Korea National Health and Nutrition Examination Survey (KNHANES). Indian J Sci \& Technol 2016; 9(41): DOI: 10.17485/ijst/2016/ v9i41/103895

14. Cárdenas-Bahena Á, Velázquez-Olmedo LB, Falcón-Flores JA, García-Zámano IE, Montes-Salmerón RE, Reza-Bravo GG, Sánchez-García S. Self-perception of oral health in older adults from Mexico City. Rev Med Inst Mex Seguro Soc 2018;56(Suppl 1):S54-S63.

15. Jones JA, Kressin NR, Spiro A 3rd, Randall CW, Miller DR, Hayes C, Kazis L, Garcia RI. Self-reported and clinical oral health in users of VA health care. J Gerontol $A$ Biol Sci Med Sci 2001;56:M55-62.

16. Singh A, Purohit BM. Exploring patient satisfaction levels, self-rated oral health status and associated variables among citizens covered for dental insurance through a National Social Security Scheme in India. Int Dent J 2017;67:172-179. doi: 10.1111/idj.12285.

17. Arantes R, Frazão P. Subjective oral symptoms associated with self-rated oral health among Indigenous groups in Central-West Brazil. Community Dent Oral Epidemiol 2018; 46:352-359. doi: 10.1111/cdoe.12375.

18. Pattussi MP, Peres KG, Boing AF, Peres MA, da Costa JS. Self-rated oral health and associated factors in Brazilian elders. Community Dent Oral Epidemiol 2010;38:348-59. doi: 10.1111/j.1600-0528.2010.00542.x..

19. Peltzer K, Pengpid S. Dental health status and oral health behavior among university students from five ASEAN countries. Nagoya J Med Sci 2017;79:123-133. doi: 10.18999/nagjms.79.2.123

20. Ekbäck G, Näslund I, Montgomery SM, Ordell S. Self-perceived oral health and obesity among 65 years old in two Swedish counties. Swed Dent J 2010;34:207-15.

21. Afonso-Souza G, Nadanovsky P, Chor D, Faerstein E, Werneck GL, Lopes CS. Association between routine visits for dental checkup and self-perceived oral health in an adult population in Rio de Janeiro: the Pró-Saúde Study. Community Dent Oral Epidemiol 2007;35:393-400. 
22. Andrade FB, Lebrão ML, Santos JL, Duarte YA, Teixeira DS. Factors related to poor self-perceived oral health among community-dwelling elderly individuals in São Paulo, Brazil. Cad Saude Publica 2012;28:1965-75.

23. Armfield JM, Mejía GC, Jamieson LM. Socioeconomic and psychosocial correlates of oral health. Int Dent J 2013;63:202-9. doi: 10.1111/idj.12032.

24. Liu Y. The relationship between lifestyle and self-reported oral health among American adults. Int Dent $J$ 2014;64:46-51. doi: 10.1111/idj.12061.

25. Astatkie A, Demissie M, Berhane Y. The association of khat (Catha edulis) chewing and orodental health: A systematic review and meta-analysis. $S$ Afr Med J 2014;104(11):773-779. doi: 10.7196/samj.8070.

26. Quandt SA, Chen H, Bell RA, Savoca MR, Anderson AM, Leng X, Kohrman T, Gilbert GH, Arcury TA. Food avoidance and food modification practices of older rural adults: association with oral health status and implications for service provision. Gerontologist 2010;50(1):100-11. doi: 10.1093/geront/gnp096.

27. Novak D, Štefan L, Emeljanovas A, Mieziene B, Milanović I, Janić SR, Kawachi I. Factors associated with good self-rated health in European adolescents: a population-basedcross-sectional study. Int J Public Health 2017;62:971-979. doi: 10.1007/s00038-017-1015-0.

28. Ministry of Health. Kenya STEPwise survey for non communicable diseases risk factors 2015 report. Nairobi: Ministry of Health, 2015.

29. World Health Organization. Global physical activity questionnaire (GPAQ) analysis guide. Geneva, Switzer- land: World Health Organization, 2012.

30. World Health Organization. The STEPS Instrument and Support Materials, 2014. Available at http://www. who.int/ncds/surveillance/steps/instrument/en/ (accessed 10 May 2016).

31. World Health Organization. BMI classification, 2017. Retrieved at: http://apps who int/bmi/index jsp?introPage=intro_3 html (accessed on 1 March 2018)

32. Masalu JR, Kikwilu EN, Kahabuka FK, Mtaya M, Senkoro AR. Socio-demographic and behavioural correlates of oral health related quality of life among Tanzanian adults: a national pathfinder survey. Tanzania J Health Res 2012; 14:1-11. Doi: http://dx.doi.org/10.4314/thrb. v14i3.8

33. Song IS, Han K, Ko Y, Park YG, Ryu JJ, Park JB. Associations between the consumption of carbonated beverages and periodontal disease: The 2008-2010 Korea national health and nutrition examination survey. Medicine (Baltimore) 2016;95(28):e4253. doi: 10.1097/ MD.0000000000004253.

34. Jordão LMR, Malta DC, Freire MDCM. Clustering patterns of oral and general health-risk behaviours in Brazilian adolescents: Findings from a national survey. Community Dent Oral Epidemiol 2018;46:194-202. doi: 10.1111/cdoe.12354.

35. Liu H, Maida CA, Spolsky VW, Shen J, Li H, Zhou $\mathrm{X}$, Marcus M. Calibration of self-reported oral health to clinically determined standards. Community Dent Oral Epidemiol. 2010;38(6):527-39. doi: 10.1111/j.16000528.2010.00562.x. 